\title{
BMJ Open Multimorbidity patterns in patients with heart failure: an observational Spanish study based on electronic health records
}

Antonio Gimeno-Miguel (D) , 1,2 Anyuli Gracia Gutiérrez, ${ }^{3}$ Beatriz Poblador-Plou, ${ }^{1,2}$ Carlos Coscollar-Santaliestra, ${ }^{1,4} \mathrm{~J}$ Ignacio Pérez-Calvo, ${ }^{3,5}$ Miguel J Divo, ${ }^{6}$ Amaia Calderón-Larrañaga, ${ }^{7}$ Alexandra Prados-Torres, ${ }^{1,2}$ Fernando J Ruiz-Laiglesia ${ }^{3}$

To cite: Gimeno-Miguel A, Gracia Gutiérrez A, PobladorPlou B, et al. Multimorbidity patterns in patients with heart failure: an observational Spanish study based on electronic health records. BMJ Open 2019:9:e033174. doi:10.1136/ bmjopen-2019-033174

- Prepublication history for this paper is available online. To view these files, please visit the journal online (http://dx.doi. org/10.1136/bmjopen-2019033174).

AG-M and AGG are first coauthors.

AP-T and FJR-L are senior coauthors.

Received 23 July 2019 Revised 13 November 2019 Accepted 21 November 2019

Check for updates

(C) Author(s) (or their employer(s)) 2019. Re-use permitted under CC BY-NC. No commercial re-use. See rights and permissions. Published by BMJ.

For numbered affiliations see end of article.

Correspondence to Dr Antonio Gimeno-Miguel; agimenomi.iacs@aragon.es

\section{ABSTRACT}

Objectives To characterise the comorbidities of heart failure (HF) in men and women, to explore their clustering into multimorbidity patterns, and to measure the impact of such patterns on the risk of hospitalisation and mortality.

Design Observational retrospective population study based on electronic health records.

Setting EpiChron Cohort (Aragón, Spain).

Participants All the primary and hospital care patients of the EpiChron Cohort with a diagnosis of HF on 1 January 2011 (ie, 8488 women and 6182 men). We analysed all the chronic diseases registered in patients' electronic health records until 31 December 2011.

Primary outcome We performed an exploratory factor analysis to identify the multimorbidity patterns in men and women, and logistic and Cox proportional-hazards regressions to investigate the association between the patterns and the risk of hospitalisation in 2012, and of 3-year mortality.

Results Almost all HF patients (98\%) had multimorbidity, with an average of 7.8 chronic diseases per patient. We identified six different multimorbidity patterns, named cardiovascular, neurovascular, coronary, metabolic, degenerative and respiratory. The most prevalent were the degenerative $(64.0 \%)$ and cardiovascular $(29.9 \%)$ patterns in women, and the metabolic (49.3\%) and cardiovascular (43.2\%) patterns in men. Every pattern was associated with higher hospitalisation risks; and the cardiovascular, neurovascular and respiratory patterns significantly increased the likelihood of 3-year mortality.

Conclusions Multimorbidity is the norm rather than the exception in patients with heart failure, whose comorbidities tend to cluster together beyond simple chance in the form of multimorbidity patterns that have different impact on health outcomes. This knowledge could be useful to better understand common pathophysiological pathways underlying this condition and its comorbidities, and the factors influencing the prognosis of men and women with HF. Further large scale longitudinal studies are encouraged to confirm the existence of these patterns as well as their differential impact on health outcomes.
Strengths and limitations of this study

- This is a large-scale population-based study that included the primary and hospital care patients of the reference population with a diagnosis of HF.

- The data in the cohort continuously underwent quality control check-ups to ensure its accuracy and reliability for research purposes.

- The cross-sectional characterisation of the multimorbidity patterns made it impossible to understand the chronological relationship between the different risk factors and chronic diseases.

- Diagnoses were extracted from electronic health records that were not originally designed for research, thus leading to a potential over or under-reporting of specific diseases.

- The estimation of the effect of multimorbidity patterns on health outcomes did not consider the potential confounding role of socioeconomic factors or clinical parameters, like the ejection fraction, which were not available in the study cohort.

\section{INTRODUCTION}

Improvements in diagnostic and therapeutic procedures have decreased heart failure (HF) mortality rates, transforming this previously life-threatening condition into a chronic disease with a high burden of comorbidity, as confirmed by European HF registries. ${ }^{1}$ HF patients are complex and present different phenotypes depending on age, sex, comorbidity and pathophysiological and prognostic aspects. ${ }^{2}$ Both cardiovascular and non-cardiovascular comorbidities are determining factors in the differentiation of these phenotypes and their impact on health outcomes. In fact, HF patients with noncardiovascular comorbidities show increased disease burden, severity, risk of hospitalisation and death. ${ }^{34}$ 
Recent studies have examined the most prevalent comorbidities in HF patients and their prognostic impact on mortality rates and hospital readmissions. ${ }^{256}$ However, although the clustering of chronic diseases into multimorbidity patterns has already been demonstrated in the general population, ${ }^{7}$ most studies still focus on isolated comorbidities, without considering the interrelations among them. Some of the few studies addressing multimorbidity in HF patients restrict their analyses to the most frequently co-occurring combinations of two or three comorbidities, ${ }^{8}$ while others are conducted in relatively small samples. ${ }^{9}$ Moreover, the methodological approaches in these studies in terms of data sources, studied comorbidities and statistical techniques vary considerably. ${ }^{3-10}$ Thus, there is still a need to perform studies on real patients from primary care, where multimorbidity is most frequently dealt with, and to address the sex/gender perspective of this disease and its comorbidities.

The Academy of Medical Sciences recently highlighted the importance of investigating which multimorbidity patterns cause the greatest burden of disease, and the determinants of the most common clusters of conditions. ${ }^{11}$ Improving our knowledge on the systematic associations among HF comorbidities is of great interest, as some of them are known to share common biological and socioeconomic risk factors on which prevention strategies could be based. Furthermore, the identification and clinical characterisation of multimorbidity patterns in men and women with HF, and the study of their potential impact on negative health outcomes (eg, risk of death and hospitalisation) could shed light on new pathophysiological pathways. These pathways could help guide the development of clinical practice guidelines better adapted to patients with HF based on their sex and comorbidities. ${ }^{12}$

This large-scale population study based on electronic health records from real primary and hospital care patients aimed to characterise the comorbidities of HF in men and women, to explore their clustering into multimorbidity patterns, and to measure the impact of such patterns on negative health outcomes.

\section{METHODS}

\section{Design and study population}

We conducted a retrospective observational study based on the EpiChron Cohort, which links demographic, clinical and health outcome-related information for all public health system users of the Spanish region of Aragón. A description of the cohort profile and of the data sources was published elsewhere. ${ }^{13}$ This cohort was conformed in 2011 and it included 1253292 people at baseline (approximately 95\% of the total inhabitants of Aragón). For this study, we selected all patients with HF diagnosis in their primary or hospital electronic health records on 1 January 2011 and followed them up for 3 years.

\section{Study variables}

For each patient, we analysed demographic data (ie, age, sex, area of residence, immigration status), hospital admissions during 2012, all chronic condition diagnoses from primary and/or hospital care, and all-cause mortality until 31 December 2014. Diagnoses were extracted from the electronic health records of both primary and hospital care levels, and included all active episodes between 1 January 2011 and 31 December 2011, even if a healthcare professional had recorded them before the initial date. Diseases were originally coded according to the International Classification of Primary Care (ICPC) (in primary care settings) or the International Classification of Diseases, Ninth Revision, Clinical Modification (ICD-9-CM) (in hospital settings), and subsequently grouped into 260 mutually exclusive Expanded Diagnostic Clusters (EDCs) through the Johns Hopkins ACG System (version 11.0, The Johns Hopkins University, Baltimore, MD, US). ${ }^{14}$ We included every patient with the CAR05 EDC code, as well as the ICPC and ICD-9-CM codes for HF, and considered all 114 possible EDCs previously established as chronic by Salisbury et $a l^{15}$ for the analysis. Multimorbidity was defined as the presence of two or more EDCs from Salisbury's list.

This study complies with the Declaration of Helsinki, and the Clinical Research Ethics Committee of Aragón (CEICA) approved the research protocol (PI18/082). The CEICA waived the requirement to obtain informed consent from patients since all the information was anonymised.

\section{Statistical analyses}

All our analyses were stratified by sex. First, we performed a descriptive analysis of the demographic and clinical information of the population with HF. We compared means and frequencies using Student's t-test and the chisquared test, respectively, with their corresponding $95 \%$ confidence intervals.

Second, we applied an exploratory factor analysis to identify the existence of non-random associations among chronic diseases in men and women. To facilitate the epidemiological and clinical interpretation of the results, we only included in the analysis those chronic comorbidities from Salisbury's list with a prevalence $\geq 5 \%$ in each sex. The methodology followed was described elsewhere. ${ }^{7}$ Briefly, EDCs were coded as binary variables (present/ absent), and a factor analysis based on a tetrachoric correlation matrix was performed to determine which diagnoses comprised each factor. We used the principal factor method for the extraction of the factors, and a scree plot in combination with clinical criteria to determine the number of factors to extract. The EDCs with factor scores $\geq 0.25$ within a pattern were considered to be part of that multimorbidity pattern, so that the same EDC could be present in more than one pattern. Model goodness-of-fit and sample adequacy were calculated through the proportions of cumulative variance and the Kaiser-Meyer-Olkin (KMO) parameter. After performing 
the factor analysis, three clinical experts (FRL, CCS and APT) proposed and agreed on the denomination of the resulting patterns according to the most relevant diseases and those with the highest loading factor within each pattern. Individuals were subsequently assigned to one or more of the described patterns of multimorbidity if they had at least two of the diseases that comprised the pattern (in addition to HF), as described by Prados $e t ~ a l{ }^{7}$

Finally, we applied logistic and Cox proportionalhazards regressions to calculate the risk of having at least one hospitalisation during 2012 and of 3-year mortality, respectively, depending on the multimorbidity pattern suffered by the individual (compared with having no patterns). Patient age (continuous variable) and all the multimorbidity patterns were included as independent variables in the models. We used Kaplan-Meier survival curves to represent and compare survival rates of individuals with specific multimorbidity patterns, which were also used to test for the proportional hazard assumption.

We conducted all statistical analyses using STATA (Version 12.0, StataCorp LLC, College Sation, TX, US). Statistical significance was set at $\mathrm{p}<0.05$.

\section{Patient and public involvement}

Patients and public were not involved in this study.

\section{RESULTS}

A total of 14670 patients from the EpiChron Cohort had a HF diagnosis in 2011, representing around $1.1 \%$ of the total population of Aragón. The study population is described in table 1 . Women predominated over men $(57.9 \%$ vs $42.1 \%, \mathrm{p}<0.001)$ and were older on average (79.9 vs 75.2 years, $\mathrm{p}<0.001$ ), mainly due to a higher proportion of people aged $\geq 85$ years. The cumulative mortality rate throughout the 3-year follow-up was higher in men than in women $(36.5 \%$ vs $33.3 \%, \mathrm{p}<0.001)$, and the same pattern was observed for hospital admissions.

In our study, almost all patients with HF $(98 \%)$ suffered from multimorbidity, with an average disease burden of 7.8 chronic diseases per patient (HF included). These figures are higher than those observed in the reference cohort (38\% and 1.7 chronic diseases/patient, respectively). The most prevalent HF comorbidities were similar in women and in men, and were hypertension $(71.2 \%$ vs $65.0 \%)$, dyslipidemia (36.9\% vs $37.6 \%$ ), arthropathy ( $36.8 \%$ vs $23.9 \%$ ), cardiac arrhythmia ( $35.5 \%$ vs $42.6 \%$ ) and diabetes $(30.3 \%$ vs $32.3 \%)$. Except for hypertension, which was more frequent in women, cardiovascular comorbidities (ie, ischaemic heart disease and arrhythmias) as well as COPD, were more prevalent in men. Arthropathy, varicose veins of lower extremities, obesity, osteoporosis, dementia and depression were also highly prevalent in HF patients, especially in women.

We identified and described six multimorbidity patterns in women, which resulted from the factorial analysis, namely cardiovascular, respiratory, metabolic, coronaryischaemic, degenerative and neurovascular patterns. Men only showed five patterns, which were similar to those observed in women, with the exception of the respiratory pattern. Tables 2 and 3 describe the compositions of the multimorbidity patterns in women and men, respectively. In women, these patterns explained up to $40.5 \%$ of the cumulative total variance, with a KMO of 0.753 . In men, the patterns explained up to $37.3 \%$ of the cumulative total variance, with a KMO of 0.761 .

A high proportion of the study population was assigned to these patterns, with prevalence rates ranging from $13.5 \%$ (neurovascular) to $64.0 \%$ (degenerative) in women, and from $22.2 \%$ (neurovascular) to $49.3 \%$ (metabolic) in men. The prevalence and impact on health outcomes of such multimorbidity patterns is described in table 4 . In general, all the multimorbidity patterns were associated with an increased risk of hospitalisation during the following year (12\%-86\% increase) in both men and women compared with the absence of the pattern, except for the degenerative pattern in women. The cardiovascular, neurovascular and respiratory patterns significantly increased the likelihood of 3-year mortality (45\%$74 \%$ increase) in both sexes. The Kaplan-Meier survival curves for the population with HF according to different multimorbidity patterns are presented in figure 1.

\section{DISCUSSION}

\section{Comorbidity of Heart Failure}

The higher morbidity burden found in our population with HF when compared with the general population of the EpiChron Cohort ${ }^{13}$ could probably be explained by the differences in their age and sex distributions (mean age of 77.9 vs 44.2 years, and $57.9 \%$ vs $50.5 \%$ of women, respectively). The fact that almost the entire population with HF suffered from multimorbidity (ie, at least one comorbidity in addition to HF) could be due in part to our operationalization of multimorbidity, whereby an exceptionally comprehensive list of chronic conditions was considered. Although most studies agree in defining multimorbidity as the co-occurrence of two or more chronic conditions, different classification systems are frequently used and the number of diseases considered can vary from 5 to 335 conditions among studies. ${ }^{16} 17$ This lack of international consensus regarding the definition of multimorbidity hinders the comparison of results among studies, and the estimations of its prevalence and health impact.

In our study, ischaemic heart disease and arrhythmias were the most prevalent HF comorbidities in men, and hypertension was the most frequent in women, as previously described. ${ }^{1}$ The higher prevalence of COPD in men compared with women was probably due to the higher rates of smoking among Spanish men. ${ }^{18}$ While the estimated prevalence of COPD in the general Spanish population is $15 \%$ in men and $6 \%$ in women, ${ }^{19}$ these figures were almost doubled in our HF cohort, approaching the $25.6 \%$ described in the EAHFE-COPD Study on acute HF patients. ${ }^{20}$ The higher COPD prevalence might be 
Table 1 Demographic and clinical description of patients with heart failure $(n=14670)$

\section{Characteristics}

Women $(n=8488)$

Men ( $n=6182)$

$P$ value

Demographics

Sex (\%)

$57.9(57.1-58.7)$

$42.1(41.3-42.9)$

$<0.001$

Age interval (\%)

$\leq 44$ years
$45-64$ years
$65-84$ years
$\geq 85$ years

Urban area (vs rural) (\%)

$79.9(79.6-80.1)$

$75.2(74.8-75.5)$

$<0.001$

Immigrants (\%)

$2.34(2.02-2.67)$

$3.87(3.39-4.35)$

$6.03(5.53-6.54)$

$13.2(12.3-14.0)$

$52.6(51.5-53.6)$

$58.7(57.4-59.9)$

$39.0(38.0-40.1)$

$24.3(23.2-25.3)$

Clinical information

$55.7(54.6-56.7)$

$52.3(51.0-53.5)$

$<0.001$

$0.95(0.74-1.16)$

$1.38(1.08-1.67)$

0.017

3-year all-cause mortality (\%)

Mean number of diseases

Prevalence of comorbidities (\%)

Hypertension

Cardiac arrhythmia

Disorders of lipid metabolism

Arthropathy

Diabetes

Varicose veins of lower extremities

Emphysema, chronic bronchitis, COPD

Cardiovascular disorders, other

Ischaemic heart disease (excluding $\mathrm{AMI} \dagger$ )

Obesity

Depression

Cataract, aphakia

Surgical aftercare

Cardiac valve disorders

33.3 (32.3-34.3)

98.2 (97.9-98.4)

7.77 (7.69-7.85)

$71.2(70.2-72.1)$

$35.5(34.4-36.5)$

$36.9(35.8-37.9)$

36.8 (35.8-37.8)

30.3 (29.4-31.3)

$29.4(28.4-30.4)$

13.3 (12.6-14.0)

19.2 (18.4-20.0)

15.3 (14.5-16.0)

20.3 (19.4-21.1)

24.8 (23.8-25.7)

19.7 (18.9-20.6)

15.8 (15.0-16.6)

$17.0(16.2-17.8)$

Iron deficiency, other deficiency anemias

Osteoporosis

Cerebrovascular disease

Respiratory disorders, other

Hypothyroidism

Dementia and delirium

Prostatic hypertrophy

Dermatitis and eczema

Chronic renal failure

Glaucoma

Deafness, hearing loss

AMI†

Chronic ulcer of the skin

Hematologic disorders, other

Asthma

Low back pain

Gout
17.3 (16.5-18.1)

$23.1(22.2-24.0)$

$13.9(13.2-14.7)$

$12.5(11.8-13.2)$

$17.6(16.8-18.4)$

$13.3(12.6-14.0)$

$-$

$-$

$9.80(9.17-10.4)$

$8.19(7.60-8.77)$

$10.4(9.76-11.1)$

$9.57(8.94-10.2)$

$5.84(5.34-6.34)$

$7.94(7.37-8.52)$

$10.6(10.0-11.3)$

$6.54(6.01-7.06)$

$2.70(2.35-3.04)$
$10.2(9.58-10.9)$
$36.5(35.3-37.7) \quad<0.001$

$97.7(97.3-98.1) \quad 0.068$

$\begin{array}{ll}7.87(7.77-7.97) & 0.114\end{array}$

$65.0(63.8-66.2) \quad<0.001$

$42.6(41.4-43.9) \quad<0.001$

37.6 (36.4-38.8) $\quad 0.388$

$23.9(22.8-25.0) \quad<0.001$

$32.3(31.2-33.5) \quad 0.010$

$11.8(11.0-12.6) \quad<0.001$

$32.8(31.6-34.0) \quad<0.001$

$24.0(22.9-25.0) \quad<0.001$

$24.6(23.5-25.7) \quad<0.001$

$17.6(16.7-18.5) \quad<0.001$

$10.9(10.1-11.7) \quad<0.001$

$16.9(15.9-17.8) \quad<0.001$

$19.3(18.3-20.2) \quad<0.001$

$17.5(16.6-18.4) \quad 0.394$

$15.6(14.7-16.5) \quad 0.007$

$3.69(3.22-4.16) \quad<0.001$

$14.3(13.4-15.1) \quad 0.604$

$16.1(15.2-17.1) \quad<0.001$

$6.44(5.83-7.05)<0.001$

$8.44(7.75-9.14) \quad<0.001$

$24.6(23.5-25.7)$

$10.3(9.58-11.1)$

0.287

$12.3(11.5-13.1) \quad<0.001$

$8.61(7.91-9.30)<0.001$

$9.17(8.45-9.89) \quad 0.419$

$13.8(12.9-14.6) \quad<0.001$

$7.40(6.74-8.04)<0.001$

$9.43(8.70-10.2) \quad 0.002$

$4.69(4.16-5.22) \quad<0.001$

$6.10(5.50-6.69) \quad 0.280$

$10.5(9.75-11.3) \quad<0.001$ 
Table 1 Continued

\begin{tabular}{cccc}
\hline Characteristics & Women $(\mathbf{n = 8 4 8 8})$ & Men $(\mathbf{n}=\mathbf{6 1 8 2})$ & $\mathbf{P}$ value \\
\hline Neurologic disorders, other & $6.63(6.10-7.16)$ & $5.10(4.55-5.64)$ & $<0.001$ \\
Diverticular disease of colon & $5.75(5.25-6.24)$ & $4.82(4.29-5.35)$ & 0.014 \\
Other endocrine disorders & $5.96(5.46-6.47)$ & $3.80(3.32-4.28)$ & $<0.001$ \\
\hline
\end{tabular}

95\% confidence intervals are displayed within brackets. Only comorbidities with a mean prevalence equal to or greater than $5 \%$ are displayed.

${ }^{*}$ Defined as having two or more chronic conditions from a list of 114 chronic diagnoses.

†Acute myocardial infarction.

explained because a) both COPD and HF share similar symptoms; b) beta-blockers (indicated for HF) and bronchodilators (indicated for COPD) have an effect on both pathologies; and c) heart congestion alters pulmonary function tests, among others. In this regard, a study found that congestive heart failure is strongly associated with comorbidities that may lead to the misdiagnosis and, more specifically, over-diagnosis of COPD in these patients. $^{21}$

Comorbid depression, which was predominantly observed in women, presented a prevalence 2-3 times higher than that observed in the general population. ${ }^{13}$ Its prevalence is consistent with that reported in the meta-analytic review by Rutledge $e t a l,{ }^{22}$ where the mean prevalence of depression in HF patients was $21.5 \%$. Depression has been associated to worse prognosis in patients with cardiovascular disease in terms of mortality, hospital admissions and functional status. ${ }^{1}$ However, its role as a potential risk factor for the development of HF is less consistent; so far, this has only been proven in women and in older patients with systolic hypertension. ${ }^{23}$ The greater prevalence of hypothyroidism observed in HF patients compared with that of the population aged $\geq 65$ years from the same reference cohort $(3.1 \%$ in men; $12.7 \%$ in women $)^{13}$ could be partially explained by the structural and haemodynamic secondary effects of the lack of thyroid hormones on the heart. The higher prevalence of hypothyroidism observed in women compared with men is congruent with the results from the Euro Heart Failure Survey II. ${ }^{19}$

The clinical composition of the multimorbidity patterns found in the study and their impact on mortality and hospitalisation is discussed below. In general, the number and type of patterns obtained in men and women were very similar, although their prevalence, composition and impact on health outcomes differed moderately.

\section{Cardiovascular pattern}

This pattern mainly included cardiac arrhythmia, cardiac valve disorders and hematologic disorders (eg, anticoagulant therapy), as well as chronic renal failure and anaemia. Kidney and heart diseases share common risk factors and they are interrelated through adaptive mechanisms. Moreover, chronic failure of both organs, volume overload, increased levels of cytokines, malabsorption syndrome, suppression of the bone marrow and anticoagulant therapy increase the frequency of anaemia in HF patients. ${ }^{24}$ The presence of these comorbidities in the cardiovascular but not in the coronaryischaemic pattern could imply a greater deterioration in HF patients suffering from the former pattern. In fact, patients presenting the cardiovascular pattern showed significantly higher risk of hospitalisation and mortality in both sexes. The strong association of this pattern with hospitalisation could probably be due to the haemodynamic dysfunction produced by cardiac arrhythmias and anaemia, which often leads to decompensation and subsequent hospitalisation. ${ }^{25}$

\section{Respiratory pattern}

The absence of a specific respiratory pattern in men is remarkable, as is the absence of COPD in the rest of patterns, considering the acknowledged association between COPD and ischaemic heart disease, ${ }^{26}$ both related to HF, and the high prevalence of COPD particularly in men. Ahmad et $a l^{27}$ found that COPD appeared in several clusters of patients with $\mathrm{HF}$, especially in those with higher morbidity burden, which also clustered with ischaemic heart disease, cerebrovascular disease, smoking and male sex. In our study, COPD did not come up as part of any pattern in men, suggesting a lack of discriminative power of this disease in terms of disease clustering in men with HF. Nevertheless, this pattern had the second-highest impact on both mortality and hospitalisation in women.

\section{Metabolic pattern}

This pattern, which was the most prevalent in both sexes, included risk factors present in the so-called metabolic syndrome. This pattern has been consistently identified across studies carried out in the general population, and in $18 \%$ of patients with HF, with no gender differences. ${ }^{28}$ The fact that only two diseases had to be present to assign patients to the metabolic pattern could justify its higher prevalence. When this pattern was restricted to presenting three or more conditions, its prevalence decreased to $21.3 \%$ in women and $22.1 \%$ in men, which is closer to previously published prevalence rates. The absence of an association of this pattern with increased 3-year mortality both in men and women is in line with existing literature, probably due to reverse epidemiology whereby HF patients with cardiovascular risk factors have better prognosis. ${ }^{29}$ 
Table 2 Multimorbidity patterns identified in women with heart failure $(n=8488)$. Each pattern is represented by the comorbidities and their loading factors in the pattern

\begin{tabular}{|c|c|c|}
\hline Patterns & Comorbidities & $\begin{array}{l}\text { Loading } \\
\text { factors }\end{array}$ \\
\hline \multirow[t]{7}{*}{ Cardiovascular } & Cardiac arrhythmia & 0.80 \\
\hline & Cardiac valve disorders & 0.62 \\
\hline & Cardiovascular disorders, other & 0.58 \\
\hline & Hematologic disorders, other & 0.52 \\
\hline & Surgical aftercare & 0.33 \\
\hline & Cardiomyopathy & 0.32 \\
\hline & Chronic renal failure & 0.29 \\
\hline \multirow[t]{6}{*}{ Respiratory } & Respiratory disorders, other & 0.47 \\
\hline & $\begin{array}{l}\text { Emphysema, chronic bronchitis, } \\
\text { COPD }\end{array}$ & 0.47 \\
\hline & Asthma & 0.42 \\
\hline & Other endocrine disorders & 0.37 \\
\hline & Chronic renal failure & 0.30 \\
\hline & Surgical aftercare & 0.25 \\
\hline \multirow[t]{5}{*}{ Metabolic } & Diabetic retinopathy & 0.74 \\
\hline & Diabetes & 0.73 \\
\hline & Obesity & 0.40 \\
\hline & Hypertension & 0.36 \\
\hline & Disorders of lipid metabolism & 0.26 \\
\hline \multirow{3}{*}{$\begin{array}{l}\text { Coronary- } \\
\text { ischaemic }\end{array}$} & Acute myocardial infarction & 0.76 \\
\hline & $\begin{array}{l}\text { Ischaemic heart disease } \\
\left(\text { excluding } \mathrm{AMI}^{\star}\right)\end{array}$ & 0.66 \\
\hline & Surgical aftercare & 0.30 \\
\hline \multirow[t]{8}{*}{ Degenerative } & $\begin{array}{l}\text { Varicose veins of lower } \\
\text { extremities }\end{array}$ & 0.53 \\
\hline & Arthropathy & 0.53 \\
\hline & Cataract, aphakia & 0.45 \\
\hline & Osteoporosis & 0.34 \\
\hline & Thrombophlebitis & 0.29 \\
\hline & Deafness, hearing loss & 0.26 \\
\hline & Obesity & 0.25 \\
\hline & Hypertension & 0.25 \\
\hline \multirow[t]{5}{*}{ Neurovascular } & Dementia and delirium & 0.76 \\
\hline & Chronic ulcer of the skin & 0.48 \\
\hline & Cerebrovascular disease & 0.41 \\
\hline & Chronic renal failure & 0.28 \\
\hline & Respiratory disorders, other & 0.25 \\
\hline
\end{tabular}

*Acute myocardial infarction.

\section{Coronary-ischemic pattern}

This pattern was, along with the metabolic pattern, one of the most consistent patterns from a clinical standpoint. The evolution from micro- and macro-vascular endothelial damage caused by arteriosclerosis to myocardial injury represents a pathophysiological continuum
Table 3 Multimorbidity patterns identified in men with heart failure $(n=6182)$. Each pattern is represented by the comorbidities and their loading factors in the pattern

\begin{tabular}{|c|c|c|}
\hline Patterns & Comorbidities & $\begin{array}{l}\text { Loading } \\
\text { factors }\end{array}$ \\
\hline \multirow[t]{9}{*}{ Cardiovascular } & Cardiovascular disorders, other & 0.66 \\
\hline & Cardiac arrhythmia & 0.64 \\
\hline & Cardiac valve disorders & 0.58 \\
\hline & Cardiomyopathy & 0.55 \\
\hline & Surgical aftercare & 0.46 \\
\hline & Hematologic disorders, other & 0.39 \\
\hline & Respiratory disorders, other & 0.39 \\
\hline & Chronic renal failure & 0.33 \\
\hline & $\begin{array}{l}\text { Iron deficiency, other deficiency } \\
\text { anemias }\end{array}$ & 0.26 \\
\hline \multirow[t]{8}{*}{ Neurovascular } & Dementia and delirium & 0.54 \\
\hline & Generalised atherosclerosis & 0.52 \\
\hline & Peripheral vascular disease & 0.46 \\
\hline & Chronic renal failure & 0.45 \\
\hline & Cerebrovascular disease & 0.43 \\
\hline & Respiratory disorders, other & 0.43 \\
\hline & Chronic ulcer of the skin & 0.39 \\
\hline & $\begin{array}{l}\text { Iron deficiency, other deficiency } \\
\text { anemias }\end{array}$ & 0.39 \\
\hline \multirow[t]{5}{*}{ Metabolic } & Obesity & 0.71 \\
\hline & Diabetes & 0.45 \\
\hline & Hypertension & 0.45 \\
\hline & Disorders of lipid metabolism & 0.40 \\
\hline & Substance use & 0.31 \\
\hline \multirow[t]{4}{*}{$\begin{array}{l}\text { Coronary- } \\
\text { ischaemic }\end{array}$} & $\begin{array}{l}\text { Ischaemic heart disease (excluding } \\
\text { AMI*) }^{*}\end{array}$ & 0.70 \\
\hline & Acute myocardial infarction & 0.70 \\
\hline & Surgical aftercare & 0.36 \\
\hline & Disorders of lipid metabolism & 0.36 \\
\hline \multirow[t]{7}{*}{ Degenerative } & Arthropathy & 0.43 \\
\hline & Cataract, aphakia & 0.42 \\
\hline & Deafness, hearing loss & 0.39 \\
\hline & Glaucoma & 0.31 \\
\hline & Varicose veins of lower extremities & 0.30 \\
\hline & Dermatitis and eczema & 0.30 \\
\hline & Prostatic hypertrophy & 0.26 \\
\hline
\end{tabular}

*Acute myocardial infarction.

underlying this pattern. However, our study could not test this hypothesis since the medical history of HF patients was unknown. Previous studies have corroborated the late appearance of ischaemic heart disease in women with diabetes and hypertension, whereas, in men, this condition appears earlier and in association to myocardial infarction and smoking. ${ }^{30}$ The absence of association with 3-year mortality may be explained by the effectiveness of 
Table 4 Prevalence of multimorbidity patterns identified in men $(n=6182)$ and women $(n=8488)$ with heart failure, and adjusted associations with hospitalisation and death

\begin{tabular}{|c|c|c|c|c|c|c|}
\hline Multimorbidity pattern & $\begin{array}{l}\text { Prevalence } \\
(\%)\end{array}$ & $\begin{array}{l}\text { Mean age } \\
\text { (years) }\end{array}$ & Hospitalisation (OR) ${ }^{\star}$ & $P$ value & Death (HR) $\dagger$ & $P$ value \\
\hline \multicolumn{7}{|l|}{ Women } \\
\hline Cardiovascular & 29.9 & 80.4 & $1.86(1.66-2.08)$ & $<0.001$ & $1.45(1.33-1.58)$ & $<0.001$ \\
\hline Metabolic & 49.9 & 80.1 & $1.26(1.13-1.39)$ & $<0.001$ & $1.04(0.97-1.13)$ & 0.284 \\
\hline Coronary-ischaemic & 6.60 & 80.7 & $1.48(1.23-1.79)$ & $<0.001$ & $1.13(0.99-1.30)$ & 0.061 \\
\hline Neurovascular & 13.6 & 84.1 & $1.12(0.97-1.30)$ & 0.117 & $1.62(1.48-1.78)$ & $<0.001$ \\
\hline Degenerative & 64.0 & 81.1 & $1.19(1.06-1.32)$ & 0.002 & $0.70(0.65-0.76)$ & $<0.001$ \\
\hline Respiratory & 16.9 & 81.0 & $1.71(1.50-1.97)$ & $<0.001$ & $1.53(1.39-1.69)$ & $<0.001$ \\
\hline \multicolumn{7}{|l|}{ Men } \\
\hline Cardiovascular & 43.2 & 76.8 & $1.83(1.62-2.07)$ & $<0.001$ & $1.60(1.46-1.76)$ & $<0.001$ \\
\hline Metabolic & 49.3 & 75.3 & $1.37(1.22-1.53)$ & $<0.001$ & $0.98(0.90-1.07)$ & 0.695 \\
\hline Coronary-ischaemic & 24.7 & 76.2 & $1.25(1.10-1.43)$ & 0.001 & $0.99(0.90-1.09)$ & 0.818 \\
\hline Neurovascular & 22.2 & 79.9 & $1.62(1.41-1.86)$ & $<0.001$ & $1.74(1.58-1.91)$ & $<0.001$ \\
\hline Degenerative & 29.2 & 80.2 & $1.03(0.91-1.16)$ & 0.687 & $0.75(0.68-0.81)$ & $<0.001$ \\
\hline
\end{tabular}

${ }^{*}$ OR for having at least one hospitalisation during the following year (compared with not having the pattern).

†HR for all-cause death after 3 years of follow-up (compared with not having the pattern).

beta-blockers, aldosterone antagonists and angiotensinconverting enzyme inhibitors in reducing the risk of sudden death and prolonging survival in patients with $\mathrm{HF},{ }^{31}$ although this hypothesis needs further investigation based on longer follow-up periods.

\section{Neurovascular pattern}

This pattern included conditions related to arteriosclerotic damage in target organs (ie, kidneys, extremities and brain) and thromboembolisms secondary to cardiac arrhythmia. The presence of dementia in this pattern is not unexpected. The relationship between cognitive impairment and HF is well known, and is secondary to low cerebral perfusion, atrial fibrillation and brain changes consequent to the neuro-hormonal adaptation mechanisms underlying $\mathrm{HF}^{32}$ Patients with this pattern had among the highest risks of 3-year mortality. However, the lack of impact on women's hospitalisation risk was unexpected, especially bearing in mind that
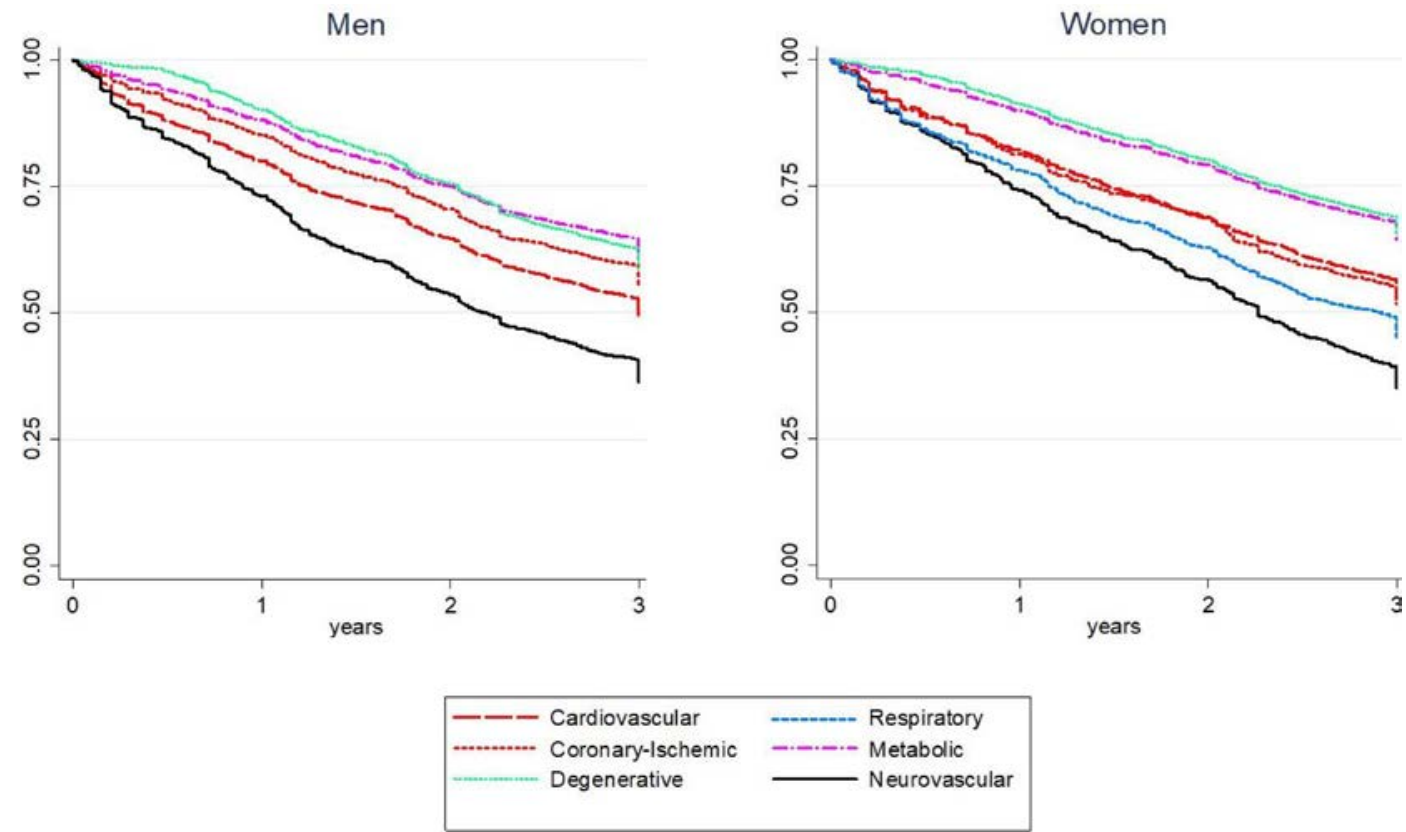

Figure 1 Kaplan-Meier survival curves in men $(n=6182)$ and women $(n=8488)$ with heart failure according to the presence of different patterns of multimorbidity. 
women suffering from this pattern were considerably older.

\section{Degenerative pattern}

This pattern, predominantly described in women, included degenerative conditions such as arthropathy, cataracts, aphakia, and hearing loss. Although this pattern would be expected to entail a greater degree of dependency than others, in the longitudinal 9-year study of Jackson $e t a l,{ }^{33}$ the neurological and cardiovascular patterns derived in greater limitations on activities of daily living compared with the degenerative pattern identified by these authors. The co-occurrence of venous disease, thrombophlebitis, osteoporosis and dermatitis in this pattern could be conditioned by the physical activity restrictions of patients with HF. This pattern was the only one associated to a decreased risk of 3-year mortality in both men and women, maybe due to the lower clinical severity of the conditions conforming it, some of which are typical of older age.

Overall, our results reflect the importance of taking the complete constellation of diseases that surrounds HF into account in both its study and clinical management. Comorbidities have been found to cluster similarly in both sexes; however, some relevant differences have emerged in the composition of the patterns and its impact on health outcomes. Although exploratory, these findings may provide important clues on which specific comorbidities or disease combinations should be given more attention in men and women with HF in order to better orient disease prevention and control strategies. Specifically, it seems that clinicians should pay particular attention to the presence of neurovascular and other cardiovascular comorbidities in both men and women, and to respiratory diseases in the case of women, to try to minimise their impact on health outcomes.

\section{Strengths and limitations of the study}

The main strength of this study is that it represents a largescale population including real primary and hospital care patients with a diagnosis of HF. Moreover, HF comorbidities were comprehensively studied by using an exhaustive list of chronic conditions, and not only the most prevalent or severe ones.

One of the main limitations of the study is the crosssectional characterisation of the multimorbidity patterns that makes it impossible to understand the chronological relationship between the different risk factors and chronic diseases. Furthermore, this work is exploratory in its approach and methodology. The estimation of the effect of multimorbidity patterns on health outcomes did not consider the potential confounding role of socioeconomic factors or clinical parameters, like the ejection fraction, which were not available in the study cohort. Other variables such as lifestyle habits (eg, smoking and drinking behaviours) were also unavailable. Diagnoses were based on real data extracted from electronic health records that were not originally designed for research, thus leading to a potential over or under-reporting of specific diseases. In this regard, data in the EpiChron cohort undergoes continuous quality control check-ups that ensure its accuracy and reliability for research purposes.

\section{CONCLUSION}

This study confirmed that multimorbidity is the norm rather than the exception in patients with heart failure, and that comorbidities tend to cluster together beyond simple chance in the form of multimorbidity patterns that impact health outcomes differently in men and women. This knowledge could be useful to better understand common pathophysiological pathways underlying this disease and its comorbidities, and the factors that influence the prognosis of these patients. Further large scale longitudinal studies are encouraged to confirm the existence of these patterns as well as their differential impact on health outcomes.

\section{Author affiliations}

${ }^{1}$ EpiChron Research Group. IIS Aragón, Aragon Health Sciences Institute, Zaragoza, Spain

${ }^{2}$ REDISSEC, Zaragoza, Spain

${ }^{3}$ Research Group on Heart Failure, IIS Aragón, Internal Medicine Service, Lozano Blesa University Hospital, Zaragoza, Spain

${ }^{4}$ Primary Care Health Centre San Pablo, SALUD, Zaragoza, Spain

${ }^{5}$ University of Zaragoza Faculty of Medicine, Zaragoza, Spain

${ }^{6}$ Pulmonary and Critical Care Division, Brigham and Women's Hospital, Harvard Medical School, Boston, Massachusetts, USA

${ }^{7}$ Aging Research Center, Department of Neurobiology, Care Sciences and Society, Karolinska Institutet, Stockholm University, Stockholm, Sweden

Acknowledgements The authors sincerely thank Eva Giménez Labrador for her statistical support and Kevin Bliek Bueno for his writing assistance.

Contributors APT and FJRL were the Principal Investigators of the study. AGM, AGG, APT and FJRL contributed to the design of the research. AGM and BPP performed the statistical analyses. APT, FJRL, AGG and CCS interpreted and discussed the results. AGM and AGG prepared the first draft of the manuscript. ACL, MJD and JIPC made important contributions to the revision of the manuscript. All authors read and approved the final version of the manuscript.

Funding This work was supported by Gobierno de Aragón [B01_17R] and the European Regional Development Fund 'Construyendo Europa desde Aragón'. The funders played no role in the design of the study, collection, analysis, and interpretation of data, or preparation of the manuscript.

Competing interests None declared.

Patient consent for publication Not required.

Ethics approval This study was approved by the Clinical Research Ethics Committee of Aragón (CEICA, Pl18/082).

Provenance and peer review Not commissioned; externally peer reviewed. Data availability statement Data are available upon reasonable request.

Open access This is an open access article distributed in accordance with the Creative Commons Attribution Non Commercial (CC BY-NC 4.0) license, which permits others to distribute, remix, adapt, build upon this work non-commercially, and license their derivative works on different terms, provided the original work is properly cited, appropriate credit is given, any changes made indicated, and the use is non-commercial. See: http://creativecommons.org/licenses/by-nc/4.0/.

ORCID iD

Antonio Gimeno-Miguel http://orcid.org/0000-0002-5440-1710 


\section{REFERENCES}

1 Lawson CA, Solis-Trapala I, Dahlstrom U, et al. Comorbidity health pathways in heart failure patients: a sequences-of-regressions analysis using cross-sectional data from 10,575 patients in the Swedish heart failure registry. PLoS Med 2018;15:e1002540doi.

2 Kajimoto K, Sato N, Takano T, et al. Relation of left ventricular ejection fraction and clinical features or co-morbidities to outcomes among patients hospitalized for acute heart failure syndromes. Am J Cardiol 2015;115:334-40.

3 Horiuchi Y, Tanimoto S, Latif AHMM, et al. Identifying novel phenotypes of acute heart failure using cluster analysis of clinical variables. Int J Cardiol 2018;262:57-63.

4 Manemann SM, Chamberlain AM, Boyd CM, et al. Multimorbidity in heart failure: effect on outcomes. J Am Geriatr Soc 2016;64:1469-74.

5 Shah SJ, Katz DH, Selvaraj S, et al. Phenomapping for novel classification of heart failure with preserved ejection fraction. Circulation 2015;131:269-79.

6 van Deursen VM, Urso R, Laroche C, et al. Co-Morbidities in patients with heart failure: an analysis of the European heart failure pilot survey. Eur J Heart Fail 2014;16:103-11.

7 Prados-Torres A, Poblador-Plou B, Calderón-Larrañaga A, et al. Multimorbidity patterns in primary care: interactions among chronic diseases using factor analysis. PLoS One 2012;7:e32190.

8 Saczynski JS, Go AS, Magid DJ, et al. Patterns of comorbidity in older adults with heart failure: the cardiovascular research network preserve study. J Am Geriatr Soc 2013;61:26-33.

9 Chamberlain AM, St. Sauver JL, Gerber Y, et al. Multimorbidity in heart failure: a community perspective. Am J Med 2015;128:38-45

10 Leva F, Bitonti D. Network analysis of comorbidity patterns in heart failure patients using administrative data. Epidemiol Biostat Public Heal 2018;15.

11 The Academy of Medical Sciences. Multimorbidity: a priority for global health research. London (UK), 2018. https://acmedsci.ac.uk/ file-download/82222577

12 Muth C, Kirchner H, van den Akker M, et al. Current guidelines poorly address multimorbidity: pilot of the interaction matrix method. J Clin Epidemiol 2014;67:1242-50.

13 Prados-Torres A, Poblador-Plou B, Gimeno-Miguel A, et al. Cohort profile: the epidemiology of chronic diseases and multimorbidity. The EpiChron cohort study. Int J Epidemiol 2018;47:382-4.

14 The Johns Hopkins ACG® system. Available: https://www. hopkinsacg.org/ [Accessed 8 Aug 2017].

15 Salisbury C, Johnson L, Purdy S, et al. Epidemiology and impact of multimorbidity in primary care: a retrospective cohort study. $\mathrm{Br} \mathrm{J}$ Gen Pract 2011;61:e12-21.

16 Fortin M, Stewart M, Poitras M. Maddocks H. a systematic review of prevalence studies on multimorbidity: toward a more uni- form methodology. Ann Fam Med 2012;2012:142-51.
17 van den Akker M, Buntinx F, Metsemakers JFM, et al. Multimorbidity in general practice: prevalence, incidence, and determinants of co-occurring chronic and recurrent diseases. J Clin Epidemiol 1998;51:367-75.

18 Fernandez E, Schiaffino A, Borràs JM, et al. Prevalence of cigarette smoking by birth cohort among males and females in Spain, 19101990. Eur J Cancer Prev 2003;12:57-62.

19 Miravitlles M, Soriano JB, Garcia-Rio F, et al. Prevalence of COPD in Spain: impact of undiagnosed COPD on quality of life and daily life activities. Thorax 2009;64:863-8.

20 Jacob J, Tost J, Miró Òscar, et al. Impact of chronic obstructive pulmonary disease on clinical course after an episode of acute heart failure. EAHFE-COPD study. Int J Cardiol 2017;227:450-6.

21 Spero K, Bayasi G, Beaudry L, et al. Overdiagnosis of COPD in hospitalized patients. Int J Chron Obstruct Pulmon Dis 2017;12:2417-23.

22 Rutledge T, Reis VA, Linke SE, et al. Depression in heart failure. J Am Coll Cardiol 2006;48:1527-37.

23 Van der Kooy K, van Hout H, Marwijk H, et al. Depression and the risk for cardiovascular diseases: systematic review and meta analysis. Int J Geriatr Psychiatry 2007;22:613-26.

24 Senni M, Paulus WJ, Gavazzi A, et al. New strategies for heart failure with preserved ejection fraction: the importance of targeted therapies for heart failure phenotypes. Eur Heart J 2014;35:2797-815.

25 Formiga F, Chivite D, Manito N, et al. Hospitalization due to acute heart failure. Role of the precipitating factors. Int J Cardiol 2007;120:237-41.

26 Divo MJ, Celli BR, Poblador-Plou B, et al. Chronic obstructive pulmonary disease (COPD) as a disease of early aging: evidence from the EpiChron cohort. PLoS One 2018;13:e0193143.

27 Ahmad T, Pencina MJ, Schulte PJ, et al. Clinical Implications of Chronic Heart Failure Phenotypes Defined by Cluster Analysis. J Am Coll Cardiol 2014;64:1765-74.

28 Wang J, Sarnola K, Ruotsalainen S, et al. The metabolic syndrome predicts incident congestive heart failure: a 20-year follow-up study of elderly Finns. Atherosclerosis 2010;210:237-42.

29 Perrone-Filardi P, Savarese G, Scarano M, et al. Prognostic impact of metabolic syndrome in patients with chronic heart failure: data from GISSI-HF trial. Int J Cardiol 2015;178:85-90.

30 Ferrari R, Abergel H, Ford I, et al. Gender- and age-related differences in clinical presentation and management of outpatients with stable coronary artery disease. Int J Cardiol 2013;167:2938-43.

31 Allen LA. Observational Process-Outcome associations for realworld ambulatory heart failure care. Circulation 2011;123:1581-3.

32 Angermann CE, Frey A, Ertl G. Cognition matters in cardiovascular disease and heart failure. Eur Heart $J$ 2012;33:1721-3.

33 Jackson CA, Jones M, Tooth L, et al. Multimorbidity patterns are differentially associated with functional ability and decline in a longitudinal cohort of older women. Age Ageing 2015;44:810-6. 